\title{
Milk lipid composition and structure; The relevance for infant brain development ${ }^{\text {is }}$
}

\author{
Lidewij Schipper ${ }^{1,2, *}$, Gertjan van Dijk ${ }^{2}$ and Eline M.van der Beek ${ }^{1,3}$ \\ ${ }^{1}$ Danone Nutricia Research, Utrecht, The Netherlands \\ 2 GELIFES, Groningen Institute for Evolutionary Life Sciences, University of Groningen, Groningen, The Netherlands \\ ${ }^{3}$ Department of Pediatrics, University Medical Center Groningen, University of Groningen, Groningen, The Netherlands
}

Received 5 November 2019 - Accepted 1 January 2020

\begin{abstract}
The neurocognitive development of infants can be positively associated with breastfeeding exclusivity and duration. Differences in dietary lipid quality between human milk and infant milk formula may contribute to this effect. In this review, we describe some of the known differences between human milk and infant milk formula in lipid quality, including fatty acid composition, complex lipids in the milk fat globule membrane as well as the physical properties of lipids and lipid globules. We describe some of the underlying mechanism by which these aspects of lipid quality are thought to modulate infant brain development such as differences in the supply and/or the bioavailability of lipids, lipid bound components and peripheral organ derived neurodevelopmental signals to the infant brain after ingestion and on longer term.
\end{abstract}

Keywords: human milk / infant milk formula / lipid composition / lipid structure / infant brain development

Résumé - Composition et structure des lipides du lait; importance pour le développement du cerveau du nourrisson. Le développement neurocognitif des nourrissons peut être associé de façon positive à l'exclusivité et à la durée de l'allaitement. Les différences qualitatives des lipides alimentaires entre le lait humain et les préparations lactées pour nourrissons pourraient contribuer à cet effet. Dans la présente étude, nous décrivons certaines des différences connues entre le lait humain et les préparations pour nourrissons en ce qui concerne la qualité des lipides, y compris la composition en acides gras, les lipides complexes de la membrane des globules gras du lait ainsi que les propriétés physiques des lipides et des globules lipidiques. Nous décrivons certains des mécanismes sous-jacents par lesquels ces aspects qualitatifs des lipides pourraient moduler le développement du cerveau du nourrisson, comme les différences dans l'apport et/ou la biodisponibilité des lipides, des composants liés aux lipides et des signaux de neuro-développement issus d'organes périphériques et allant au cerveau du nourrisson juste après l'ingestion et à plus long terme.

Mots clés : lait maternel / préparation lactée pour nourrisson / composition lipidique / structure lipidique / développement du cerveau du nourrisson

\section{Infant feeding mode and neurocognitive development}

For mammals, the first and only source of nutrition directly after birth is maternal milk. For humans, the current recommendations by the World Health Organization (WHO) for infant feeding are to exclusively breastfeed infants up to at

\footnotetext{
Contribution to the Topical Issue "Lipids and health / Lipides et santé".

*Correspondence: lidewij.schipper@danone.com
}

least 6 months of age, with continued breastfeeding along with appropriate complementary foods up to 2 years of age or beyond. Although most mothers start breastfeeding, many children do not receive mothers own milk exclusively for 6 months (World Health Organization (WHO), 2017). When mothers do not breastfeed for medical or other reasons, Infant Milk Formula (IMF) should provide an adequate alternative. Whereas human milk and IMF may be similar in energy content and macronutrient composition that are needed for infant growth and development, breast fed infants appear to have several advantages over formula fed infants when it 
comes to (long-term) health outcomes including immune, gut and metabolic health (Harder et al., 2005; Jackson and Nazar, 2006; Guaraldi and Salvatori, 2012). Regarding brain development, there are several reports that show that breastfeeding exclusivity and duration can be positively associated with e.g. brain structural development (Deoni et al., 2013, 2018; Herba et al., 2013; Kafouri et al., 2013), cognitive function (Anderson et al., 1999; Belfort et al., 2013; Leventakou et al., 2015), behaviour, school performance (Heikkila et al., 2014) and food intake regulation (Li et al., 2010; DiSantis et al., 2011). This suggests that factors beyond bulk nutritional constituents contribute to the differences observed between breast- and formula-fed infants. Indeed, brain development and function can be influenced by the behavioral aspects of infant feeding (e.g. breast vs bottle feeding (Li et al., 2010; DiSantis et al., 2011), feeding on demand $v s$ fixed schedule (Iacovou and Sevilla, 2013), selfregulation $v s$ parental encouragement for bottle emptying ( $\mathrm{Li}$ et al., 2008), mother-child bonding (Britton et al., 2006)), as well as compositional differences between human milk and formula such as the presence of bioactive components in human milk including hormones, growth factors and immune factors (Savino et al., 2009; Field, 2005; Ballard and Morrow, 2013; Grey et al., 2013). Furthermore, there are specific differences between human milk and IMF in the quality of nutrients, especially with regard to the quality of the lipid fraction. For instance, total lipid content in IMF is fixed whereas in human milk it is variable between and within individuals, changing over the course of lactation, during the day and even during a single feed (Saarela et al., 2005; Kent et al., 2006). In addition, the quality of the lipid fraction in human milk differs from that in IMF in at least two more aspects. First, the composition of individual fat components, specifically the types of fatty acids and bioactive lipid ingredients that make up the total fat content of milk, is not the same. Second, the (supra)molecular structure in which lipids are organized is substantially different between human milk and IMF. These specific aspects of lipid quality and how they may relate to infant brain development and function will be addressed in more detail below.

\section{Milk fatty acid composition}

Approximately $98 \%$ of the lipid fraction in human milk consists of triglycerides, each containing three fatty acids (FA) (Hamosh et al., 1985; Jensen et al., 1990). The majority of FA in human milk are saturated fatty acids (SFA) (German and Dillard, 2010), followed by mono-unsaturated fatty acids (MUFA) and about $20 \%$ of the FA in human milk are omega (n)-3 or n-6 polyunsaturated fatty acids (PUFA). These include longer chain PUFA (carbon chain-length $>20$, LCPUFA) of the n-6 and n-3 family, such as arachidonic acid (C20:4 n-6; ARA) and docosahexanoic acid (C22:6 n-3; DHA), as well as their respective $\mathrm{C} 18$ precursors linoleic acid (C18:2 n-6; LA) and alpha-linolenic acid (C18:3 n-3; ALA) that can be converted to LCPUFA after ingestion (Salem et al., 1996).

Whereas the proportion of SFA and MUFA in (mature) human milk are relatively constant, the (LC)PUFA profile may vary in relation to maternal dietary fatty acid intake and fatty acids released from maternal adipose tissue stores or the liver
(Makrides et al., 1995; Innis, 2007). In particular, maternal dietary intake of ALA, LA and DHA affects the amounts of these specific PUFA in human milk (Koletzko et al., 1992; Yuhas et al., 2006). For instance, the marked increase in dietary intake of LA in the past 100 years, seen in Westernindustrialized societies as a result of increased use of vegetable oils rich in LA (Kris-Etherton et al., 2000; Sanders, 2000; Wolmarans, 2009), is also reflected in higher LA content in milk of women from Europe, Australia and Northern America (Ailhaud et al., 2006; Gibson et al., 2011). Whereas the recommendations for fatty acid composition in IMF have been based on human milk (Efsa panel, 2014), fluctuations from day to day and over the course of lactation would be difficult to mimic. Moreover, the recommended PUFA composition for IMF has been based on milk samples analysed in a small set of Caucasian women in a Western industrialized society context (Efsa panel, 2014). A debate is ongoing whether or not the FA composition in milk from this reference group can be considered the healthiest composition for infant growth and development (Kuipers et al., 2005; Ailhaud et al., 2006).

\section{Fatty acids in the brain}

Dietary supply of PUFA is essential for infant brain development and function. Nearly $60 \%$ of the dry-weight of the human brain consists of lipids (O'Brien and Sampson, 1965 ) and about $35 \%$ of the lipids in the grey matter are LCPUFA (Benatti et al., 2004). In the neuronal membrane, the LCPUFA support physical and functional membrane properties. Longer chain LCPUFA increase membrane fluidity due to their more spacious structure and influence membrane receptor, enzyme activities and neuronal plasticity (Youdim et al., 2000). The most abundant LCPUFA in the neuronal membrane are ARA and DHA, which rapidly accumulate in the human brain during the first 1000 days, supporting the rapid increase in brain volume (Martinez and Mougan, 1998). DHA and ARA contribute to membrane physical properties and have their own unique roles in brain development and function. Sufficient presence of particularly DHA in the neuronal membranes is critical as DHA contributes positively to various processes important for neuronal growth and development including modulating neural metabolism, differentiation, plasticity, neuroprotection and anti-inflammatory effects (see e.g. (Dyall, 2015) for review). ARA is the precursor for specific membrane derived eicosanoids which are important for immunity and immune responses including the regulation of neuro-inflammation (Duncan and Bazinet, 2010; Hadley et al., 2016). Other n-3 LCPUFA in the brain, though present in much lower concentration than DHA, include eicosapentaenoic acid (EPA; C20:5n-3) and docosapentaenoic acid (n-3 DPA, 22:5n-3), that also generate lipid derived mediators that play a role in the inflammatory response (Dyall, 2015) and in particular EPA stimulates neurite outgrowth during development (Robson et al., 2010). DPA from the n-6 family (n-6 DPA; 22:5n-6) is the structural homologue of DHA and typically accumulates in the brain when DHA supply is insufficient (Foot et al., 1982; Carrie et al., 2000). This compensatory mechanism ensures that the total brain volume remains the same, however, n-6 DPA cannot fulfill the specific neurodevelopmental roles of DHA 
(Novak et al., 2008; Cao et al., 2009; Robson et al., 2010; Katakura et al., 2013). High levels of n-6 DPA are therefore considered disadvantageous. Preferential accumulation of DHA in the brain occurs at high rate between the 3rd trimester up to 2 years of age, and accumulation extends into childhood and adolescence (Martinez, 1992; Carver et al., 2001). This pattern parallels active brain development and further illustrates the importance of DHA for brain development and function throughout life. Indeed, it is well-documented in animal studies that perinatal depletion of brain DHA leads to enduring abnormalities including altered morphology, neurotransmission and (long term) functional impairments including impairments in cognitive performance and visual acuity and increased risk for depression/anxiety (Neuringer et al., 1986; Greiner et al., 1999; Moriguchi et al., 2000; Ahmad et al., 2002; Carrie et al., 2002; Garcia-Calatayud et al., 2005; Chalon, 2006; Clouard et al., 2015). Importantly, once established, these alterations cannot be fully restored by supplementing with n-3 LCPUFA during later life stages (Carrie et al., 2000; Ikemoto et al., 2001; Anderson et al., 2005). In humans, a direct association between brain LCPUFA composition and behaviour or cognition is difficult to demonstrate as this would require the analysis of brain tissue. However, prospective studies have shown that fœtal cord blood DHA levels - which may serve as a proxy for brain PUFA status at birth - are inversely related to internalizing problem behaviour, hyperactivity and inattention in childhood (Krabbendam et al., 2007; Kohlboeck et al., 2011), whereas higher levels of n-3 LCPUFA are associated with better motor performance, (Bakker et al., 2009), higher scores in cognitive functioning (Bakker et al., 2003; Boucher et al., 2011) and better neurological scores (Escolano-Margarit et al., 2011). Moreover, low DHA and n-3 LCPUFA or increased n-6 LCPUFA concentration in adult brain has been related to neuropsychiatric disease (McNamara et al., 2007; Conklin et al., 2010; Hamazaki et al., 2013). These studies show that DHA in the brain is critical for brain function and mental health in humans, further highlighting the importance of sufficient DHA accumulation during infancy.

\section{Dietary fatty acids are used as building blocks for the developing brain}

The developing brain relies on the plasma pool of LCPUFA for DHA accumulation. Although the brain is able to generate some DHA by endogenous synthesis from precursor n-3 LCPUFA in glial cells (Williard et al., 2001), DHA synthesis in the brain occurs at a much lower rate than the total rate of brain accretion of DHA needed to support growth and development (Demar et al., 2005; Kitson et al., 2016). In plasma, DHA and other LCPUFA are present in two major pools;

- bound albumin, as non-esterified fatty acid (NEFA)-DHA or lysophosphatidylcholine-esterified (LPC)-DHA;

- in lipoproteins esterified to e.g. TG, PL, cholesterol, PL or other lysophospholipids.

There is no consensus on what lipid form in the plasma pool is preferentially used for accumulation in the brain (Bazinet and Laye, 2014; Chen et al., 2015; Liu et al., 2015), nor are the mechanisms agreed upon by which these various forms of circulating PUFA are delivered - either by protein-mediated and/or passive diffusion (Mitchell and Hatch, 2011). The uptake process from plasma to tissue appears to be nonselective for n- 6 and n-3 LCPUFA. The accumulation of DHA in the brain is therefore dependent on the total and relative levels of DHA and other n-3 as well as n- 6 LCPUFA in the plasma (Hibbeln et al., 2006; Igarashi et al., 2009).

In turn, the level of circulating n-3 and n-6 LCPUFA are influenced by the infant's diet. Preformed LCPUFA are present in human milk or IMF and LCPUFA can be synthesized endogenously based on the supply of the precursors LA and ALA in milk (Gibson et al., 2011). The capacity of LCPUFA synthesis from LA and ALA is low in humans (Burdge and Wootton, 2002; Brenna et al., 2009). Although infants (both preterm and term) may have a similar capacity as adults to convert LA to AA, and ALA to DHA (Innis, 2003, 2007), the activity seems insufficient to fulfill the high LCPUFA requirements needed for growth and development in infancy, in particular for DHA (Decsi and Koletzko, 1995; Giovannini et al., 1995). Preformed DHA in the infant's diet therefore is considered conditionally essential (Muskiet et al., 2004; Brenna and Carlson, 2014). Human milk contains a considerable amount of LCPUFA in preformed state. It has been suggested that one of the reasons for the advantages of breastfeeding over formula feeding regarding brain development is related to the high concentration of LCPUFA in human milk, especially the natural presence of DHA (Michaelsen et al., 2009). Postmortem studies in the past have revealed that infants fed formula without DHA had lower brain DHA levels and higher n-6 LCPUFA compared to age-matched breast-fed infants (Farquharson et al., 1992; Makrides et al., 1994; Martinez and Mougan, 1998; Jamieson et al., 1999). DHA accumulation in the infant brain is, however, not only dependent on the supply of preformed DHA in the infant diet. The biosynthesis of LCPUFA from LA and ALA in the liver and other tissues involves a series of elongation and desaturation steps. LA and ALA use the same set of enzymes for conversion to ARA and DHA and therefore compete with each other. High dietary supply of LA inhibits endogenous DHA synthesis and results in higher n-6 LCPUFA in the circulation, which further limits DHA incorporation in the developing brain as circulating n-3 and n-6 LCPUFA compete for uptake by the brain as well (Lefkowitz et al., 2005; Gibson et al., 2011). In line with this, the level of LA in human milk, independent of milk n-3 LCPUFA level, has been inversely correlated to infant cognitive development and function (Lassek and Gaulin, 2014; Bernard et al., 2015, 2017). In a piglet study, it was found that a formula containing high LA increased the accumulation of n-6 LCPUFA and reduced DHA and other n-3 LCPUFA in the brain. Moreover, increasing DHA content failed to prevent some of the impairments in the brain fatty acid profile that were induced by the high supply of LA (Novak et al., 2008). Rodent studies have shown that lowering the postnatal dietary LA supply can stimulate brain DHA accumulation (Schipper et al., 2016a), alter the structural development of neuronal networks (Schipper et al., 2013) and protect the developing brain against early life stress-induced neurocognitive impairments in adulthood (Yam et al., 2019). Due to the persistent changes in, for example, serotonergic and dopaminergic neurotransmitter systems that are linked to early life impaired brain DHA accumulation (Chalon, 2006), it has 
been hypothesized that the contemporary increase in nutritional supply of LA and low supply of DHA may also contribute to the increased incidence of neurological and psychiatric disorders such as depression and schizophrenia that has been observed over the last decades (Klerman and Weissman, 1989; Muskiet, 2010; McNamara, 2013; Grosso et al., 2014).

As can be derived from the examples described above, ensuring adequate levels of n-3 LCPUFA, as well as prevention of excessive n-6 (LC)PUFA in the infant's diet appear to support n-3LCPUFA accumulation in the brain and may thereby contribute to optimal development and functioning of the infant brain. Many studies have therefore attempted to increase infant neurocognitive outcomes by (maternal) n-3 LCPUFA supplementation. However, for healthy term infants this supplementation has not always shown clear benefits (Simmer et al., 2008; Delgado-Noguera et al., 2010; Qawasmi et al., 2012), although maternal n-3 LCPUFA supplementation during lactation seems more effective than n-3 LCPUFA supplementation of IMF (Lauritzen et al., 2016). Yet, it seems unlikely that differences between LCPUFA composition in human milk and formula alone could explain the beneficial effects of breastfeeding over formula feeding on infant health and neurodevelopmental outcomes.

\section{Milk fat globules}

Mammalian milk has a distinct lipid composition and physical structure as a result of the physiological process by which the fat globules are produced and secreted from the mammary gland. Human milk lipid droplets are large, ranging in diameter from 0.2 to more than $15 \mu \mathrm{m}$ with an average mode diameter of $4 \mu \mathrm{m}$ in mature milk (Michalski et al., 2005). Lipid globules are larger in early colostrum than in mature milk (Simonin et al., 1984; Michalski et al., 2005; Zou et al., 2012), but the size remains stable during the day (Michalski et al., 2005) and during a single feed (Zou et al., 2012). In mammary gland cells, milk triglycerides are synthesized in the endoplasmatic reticulum and aggregate in small lipid droplets that are surrounded by a single layer of polar lipids and proteins. In the cytoplasm of the mammary gland cell, several of these microlipid droplets fuse to form larger lipid droplets that migrate through the cell to their secretion site. Upon secretion, the plasma membrane of the mammary gland cell encloses the lipid droplet, resulting in a three-layer biological membrane that surrounds the large TG core, which is known as the milk fat globule membrane (MFGM) (Wooding, 1971; Mather and Keenan, 1998; Heid and Keenan, 2005; Martini et al., 2016). The composition of the MFGM equals that of other biological membranes, containing complex polar lipids such as phospholipids (PL), gangliosides, sphingomyelin and cholesterol (Lopez and Menard, 2011), which together represent the remaining $1-2 \%$ of the total lipid fraction in milk (Singh, 2006; Contarini and Povolo, 2013). The PLs are mainly located in the outer bilayer of the MFGM, while cholesterol and sphingomyelin are primarily aggregated in rigid domains in the membranes called lipid rafts (Gallier et al., 2010). The most important PLs in the MFGM are phosphatidylcholine (PC), phosphatidylethanolamine (PE), phosphatidylinositol (PI), phosphatidylserine (PS) and sphingomyelin (Contarini and Povolo, 2013; Giuffrida et al., 2013).
Whereas factory-produced composition of IMF is based on the total lipid content and fatty acid composition of human milk, it does not take into account the specific structural organization of lipid droplets seen in human milk. Due to processing steps like homogenization and emulsification in IMF production, the lipid droplets have a much smaller diameter (about $0.3-1.0 \mu \mathrm{m}$ ) compared to those seen in raw milk (Michalski et al., 2005; Ye et al., 2008). Moreover, there is no biological membrane surrounding the lipid globules in standard IMF. Most commercially available infant formulas contain only triglycerides as source of lipids although IMF's with added MFGM fragments are increasing in popularity.

\section{Milk fat globule membrane (components) as bioactive ingredient}

Although representing only a small proportion of the total lipid fraction, the natural presence of MFGM complex lipids in human milk may contribute to the differences in neurocognitive development observed between breast- and formula fed infants. Studies in rodents and piglets have shown that early life dietary supplementation with MFGM or individual MGFM components such as gangliosides and sphingomyelin can positively influence brain development and functions including neuroplasticity (Guillermo et al., 2015), myelination (Oshida et al., 2003) and cognitive performance (Wang et al., 2007; Vickers et al., 2009; Liu et al., 2014a; Guan et al., 2015). Interestingly, a recent study in growth-restricted rat pups suggested that supplementation with MFGM fragments resulted in better neurodevelopmental outcomes than supplementation with some of the individual components present in MFGM (Brink et al., 2019). Human infants born preterm showed improved neurobehavioral development during infancy when exposed to sphingomyelin-fortified milk (Tanaka et al., 2013) and healthy term infants showed improved cognitive function at 6 months of age following dietary ganglioside supplementation (Gurnida et al., 2012). Moreover, at 12 months of age, the cognitive score of infants exposed to an IMF with reduced protein density and added MFGM fragments until 6 months of age was higher than that of infants fed standard formula and closer to that of a breast fed reference group (Timby et al., 2014). It is hypothesized that the complex lipids in the MFGM may serve as building blocks and or developmental signals for the infant brain. Like LCPUFA, complex lipids in MFGM such as PL, sphingolipids, gangliosides, and cholesterol can also be found as structural components of neuronal membranes (Kracun et al., 1992; Bjorkhem and Meaney, 2004; Posse de Chaves and Sipione, 2010; Zhang and Liu, 2015). These lipids play an important role in brain development, affecting a variety of processes including neurotransmission, neurogenesis, synaptogenesis, modulating synaptic transmission, cell proliferation, and neuronal differentiation and myelination (Mauch et al., 2001; Saher et al., 2005; Palmano et al., 2015). Moreover, some of these complex lipids in MFGM contain (conditionally) essential nutrients required for brain development such as sialic acid, a component in gangliosides, and choline, present in phosphatidylcholine and sphingomyelin (Zeisel, 2000, 2004; Wang, 2012). These complex lipids may be absorbed by the intestine as whole (McJarrow et al., 2009) or as individual 
essential components after digestion, and transported to the brain where they are incorporated in neuronal membranes or used again as a precursor for de novo biosynthesis of brain lipids (Reis et al., 2016). A higher dietary supply of MFGM (components) therefore increase the presence of these lipids in the neuronal membranes. Indeed, breast-fed infants were shown to have a higher brain ganglioside and sialic acid concentration than infants that had been fed a standard formula in which the content of these components is low (Wang et al., 2003). In rats, early life supplementation with dietary gangliosides increased brain ganglioside content (Park et al., 2005; Gustavsson et al., 2010) and the brain phospholipid composition of rats artificially reared on a formula supplemented with MFGM, compared to standard formula, was closer to that of mother-reared rats (Moukarzel et al., 2018). Although there is no information available on dietary cholesterol and brain cholesterol levels in human infants, increased brain cholesterol levels were found after early life dietary supply of cholesterol in piglets (Boleman et al., 1998) and rodents (Morris and Chaikoff, 1961).

\section{The physical properties of lipids and lipid globules}

In addition to the different supply of bioactive lipid ingredients, the unique physical properties of lipids in human milk compared to that of lipids in infant formula may contribute to the beneficial effects of breastfeeding on infant brain development (Ortega-Anaya and Jimenez-Flores, 2019). The MFGM that surrounds the large lipid globule in human milk comprises a triple PL layer, each PL containing two FA tails. In human milk, about $15 \%$ of the LCPUFA are PL bound (Koletzko and Rodriguez-Palmero, 1999) while standard IMF usually contains TG only. Similar to total fat and FA composition of the TG fraction in human milk, the FA composition of the PL fraction in the MFGM is influenced by the maternal diet and the stage of lactation (Lopez et al., 2008; Zou et al., 2012). In itself, the molecular structure (i.e. PL vs TG) of dietary LCPUFA can influence the digestion and absorption kinetics after ingestion, and the subsequent bioavailability of LCPUFA in the plasma for the developing brain (Amate et al., 2001; Michalski et al., 2013). Studies in infants and healthy adult volunteers have shown that PL-bound LCPUFA in the diet, including DHA, are better absorbed than TG-bound LCPUFA (Carnielli et al., 1998; Morgan et al., 1998; Ulven et al., 2011; Ramprasath et al., 2013). The molecular structure of dietary PUFA may differentially affect their distribution in plasma fatty acid pools (NEFA, LPC, esterified) after digestion and absorption and can thereby influence the total and temporal availability for uptake by the brain (Amate et al., 2001; Kitson et al., 2016). Regardless of the plasma lipid pool, there are several preclinical studies that show that dietary PL-bound LCPUFA, including DHA, more effectively target the brain than dietary LCPUFA supplied as TG (Mathews et al., 2002; Wijendran et al., 2002; Graf et al., 2010; Liu et al., 2014b; Kitson et al., 2016). This also applies to the precursors of LCPUFA, as PL bound ALA was more effective than TG bound ALA in restoring brain DHA levels after perinatal dietary n-3 LCPUFA deficiency in rats (Delplanque et al., 2013).
Adding to molecular structure, the supramolecular structure of dietary lipids in human milk may also influence the bioavailability of PUFA for the developing brain. In human milk, lipid droplets are large and are enveloped by the MFGM, whereas lipid droplets in IMF (regardless of added MFGM ingredients) are small and do not have the complex surface area. The lipid droplet size and complexity of the surface area are factors known to affect (temporal) absorption and digestion kinetics, influencing the pattern of lipid appearance in the circulation after ingestion and thus their bioavailability for developing organs (Armand et al., 1996, 1999; Michalski et al., 2006, 2013; Bourlieu et al., 2015; van Aken, 2010). Recently, a novel concept IMF was developed with large lipid globules surrounded by a phospholipid membrane, resembling more closely the supramolecular structure of lipid droplets in human milk (Gallier et al., 2015). In adult volunteers, it was shown that consumption of this concept IMF resulted in a faster postprandial increase in plasma TG and earlier peak NEFA concentrations compared to regular IMF (Baumgartner et al., 2017). Whereas potential beneficial effects of this concept IMF on brain LCPUFA accumulation pattern early in life remain to be confirmed, it was shown that early life consumption of this concept IMF improved cognitive functions in mice during adolescence and adulthood (Schipper et al., 2016b).

Alternatively, it can be hypothesized that the supramolecular structure of lipid droplets can influence neurocognitive function via the different release gut hormones that target the brain beyond satiety regulation. Due to the changes in lipid digestion and absorption kinetics, the postprandial pattern of satiety hormones is altered (Ohlsson et al., 2014). The concept IMF that mimics the supramolecular structure of lipid droplets in human milk was also reported to evoke prolonged release of the small intestine derived satiety hormone cholecystokinin (CCK) (Baumgartner et al., 2017). CCK and other lipidinduced satiety signals have been reported to facilitate learning and memory processes (Monnikes et al., 1997; Gulpinar and Yegen, 2004; Campolongo et al., 2009). A different pattern of release during critical periods of growth and development may alter developmental trajectories of brain centres involved in neurocognitive function. Studies that compare the postprandial hormone release in infants following consumption of human milk vs IMF are limited in number but do confirm differences depending of feeding mode (Lucas et al., 1981; Salmenpera et al., 1988; Slupsky et al., 2017). Recent studies also showed that the profiles of fasting state appetite regulating hormones including insulin and leptin were different between breast- and formula-fed infants (Breij et al., 2017; Vasquez-Garibay et al., 2019). Moreover, these hormones have associated with brain development and cognitive function (Plagemann et al., 2005; Farr et al., 2015; Cato and Hershey, 2016).

\section{Influence of other organs and organ derived factors}

On the longer term, differences between breast- and formula-fed infants in growth patterns and associated differences in organ development and functions that are mediated by differences in dietary lipid quality, may also influence brain development and or function. Recent work suggests for 
instance that skeletal development is a determinant of brain development, neuronal structure and behavioural function. Bone tissue secretes the hormone osteocalcin $(\mathrm{OCN})$, which was shown to be higher in serum from breast- compared to formula-fed infants (Michaelsen et al., 1992). OCN crosses the blood brain barrier to promote synthesis of several neurotransmitters including serotonin, dopamine, NA and reduces GABA during postnatal life (Oury et al., 2013). Mice lacking OCN show increased anxiety, depression and impaired learning and memory (Oury et al., 2013). OCN synthesis is dependent on the maturity of the osteoblast and on the lipid soluble factors vitamin D and K (Skjodt et al., 1985; Gundberg et al., 2012; van Driel and van Leeuwen, 2014), of which absorption could be increased by the supramolecular structure in human milk (Bezelgues et al., 2009). Also, the generally accepted link between early life dietary supplementation with n-3 LCPUFA (and or dietary low n-6 LA exposure) and cognitive and behavioural function could be mediated, in part, by enhanced bone development. High levels of ARA-derived prostaglandin 2 were shown to impair bone formation (Baylink et al., 1993) and omega-3 fatty acid supplementation in young rats and mice amplified bone formation and OCN secretion (Watkins et al., 2000; Bonnet and Ferrari, 2011; Bonnet and Ferrari, 2015).

\section{Implications for human health}

Human infants in our modern society may face many challenges during the first 1000 days that can affect brain development and are associated with higher risks for both mental and metabolic diseases. The WHO estimates that about one-third of the adult population suffers from a mental or neurological disorder (Kessler et al., 2009) and children and adolescents are increasingly affected (Polanczyk et al., 2015). As effective treatment of mental disorders is not only time consuming and expensive, but often simply not possible, prevention is key. A preventative rather than reactive approach in management of brain disorders is crucial. Prolonged breastfeeding is associated with better neurodevelopmental outcomes (Horwood and Fergusson, 1998; Belfort et al., 2013; Heikkila et al., 2014; Horta et al., 2015; Leventakou et al., 2015), which extends into later in life higher educational/ academic performance (Horwood and Fergusson, 1998; Victora et al., 2015) and reduced risk of later mental and behavioural problems (Montgomery et al., 2006; Oddy et al., 2010; Hayatbakhsh et al., 2012). Whereas possible confounding circumstances such as differences in parental education, health and food habits cannot be fully excluded in these human trials, the published evidence so far suggests that differences in dietary lipids quality could contribute to this.

Providing a more optimal balance of $n-3$ and n-6 PUFA in early life could be instrumental. Practically, this goal can be reached through more specific dietary advice to pregnant and lactating women regarding fatty acid intake. Although the importance of (maternal) dietary intake n-3 LCPUFA for infant brain development is well known to the public, the potential adverse effects of high intakes of LA, and therefore the importance of lowering levels of LA in the (maternal) diet are not yet taken into account in current dietary recommendations. Lowering dietary intake of LA can be reached by replacing the consumption of standard vegetable oils (sunflower, soybean) and food items containing substantial LA quantities such as salad dressings and snack food by alternative food products containing oils and food products lower in LA (MacIntosh et al., 2013; Wood et al., 2013, 2014). These dietary advices are relatively simple, cheap and home-based and therefore have the potential to reach a broad public. In line with this, the regulation for fatty acid composition in nutritional products for infants and young children should be critically reviewed. For instance, the recommendations of the 2014 European Food Safety Authority Panel on Dietetic Products, Nutrition and Allergies include for LA a lower and upper bound range of 0.5 and $1.2 \mathrm{~g} / 100 \mathrm{kcal} \mathrm{IMF}$, combined with 0.05 to $0.1 \mathrm{~g} / 100 \mathrm{kcal}$ IMF for ALA, an no maximal permitted LA/ALA ratio (Efsa panel, 2014). Whereas the current recommendation now include addition of preformed DHA, but not ARA, reconsideration of the upper levels of LA in particular may be a strategy that could support healthier (brain) development of infants (Kuipers et al., 2005; Muskiet et al., 2006; Gibson et al., 2011). In addition to lipid composition, the supramolecular structure of dietary lipids may be a promising target to explore in more detail as the typical structural organization of dietary lipids in human milk, i.e. being present as large lipid droplets enveloped by the MFGM, may contribute to some of these benefits. Mimicking the supramolecular structure of lipid droplets in human milk more closely could further improve IMF lipid quality and support brain development of formula fed or mixed fed infants specifically.

\section{References}

Ahmad A, Moriguchi T, Salem N. 2002. Decrease in neuron size in docosahexaenoic acid-deficient brain. Pediatr Neurol 26(3): 210-218.

Ailhaud G, et al. 2006. Temporal changes in dietary fats: role of n-6 polyunsaturated fatty acids in excessive adipose tissue development and relationship to obesity. Prog Lipid Res 45(3): 203-236.

Amate L, Gil A, Ramirez M. 2001. Feeding infant piglets formula with long-chain polyunsaturated fatty acids as triacylglycerols or phospholipids influences the distribution of these fatty acids in plasma lipoprotein fractions. J Nutr 131(4): 1250-1255.

Anderson GJ, et al. 2005. Can prenatal N-3 fatty acid deficiency be completely reversed after birth? Effects on retinal and brain biochemistry and visual function in rhesus monkeys. Pediatr Res 58(5): 865-872.

Anderson JW, Johnstone BM, Remley DT. 1999. Breast-feeding and cognitive development: a meta-analysis. Am J Clin Nutr 70(4): 525-535.

Armand M, et al. 1996. Effect of human milk or formula on gastric function and fat digestion in the premature infant. Pediatr Res 40 (3): 429-437.

Armand M, et al. 1999. Digestion and absorption of 2 fat emulsions with different droplet sizes in the human digestive tract. Am J Clin Nutr 70(6): 1096-1106.

Bakker EC, et al. 2003. Long-chain polyunsaturated fatty acids at birth and cognitive function at 7 years of age. Eur J Clin Nutr 57 (1): 89-95.

Bakker EC, et al. 2009. Relationship between long-chain polyunsaturated fatty acids at birth and motor function at 7 years of age. Eur J Clin Nutr 63(4): 499-504.

Ballard O, Morrow AL. 2013. Human milk composition: nutrients and bioactive factors. Pediatr Clin North Am 60(1): 49-74. 
Baumgartner S, et al. 2017. Infant milk fat droplet size and coating affect postprandial responses in healthy adult men: a proof-ofconcept study. Eur J Clin Nutr.

Baylink DJ, Finkelman RD, Mohan S. 1993. Growth factors to stimulate bone formation. J Bone Miner Res 8(Suppl. 2): S565-S572.

Bazinet RP, Laye S. 2014. Polyunsaturated fatty acids and their metabolites in brain function and disease. Nat Rev Neurosci 15 (12): 771-785.

Belfort MB, et al. 2013. Infant feeding and childhood cognition at ages 3 and 7 years: effects of breastfeeding duration and exclusivity. JAMA Pediatr 167(9): 836-844.

Benatti P, et al. 2004. Polyunsaturated fatty acids: biochemical, nutritional and epigenetic properties. J Am Coll Nutr 23(4): 281-302.

Bernard JY, et al. 2015. The association between linoleic acid levels in colostrum and child cognition at 2 and 3 years in the EDEN cohort. Pediatr Res 77(6): 829-835.

Bernard JY, et al. 2017. Breastfeeding, polyunsaturated fatty acid levels in colostrum and child intelligence quotient at age 5-6 years. J Pediatr 183: 43.e3-50.e3.

Bezelgues JB, et al. 2009. Short communication: milk fat globule membrane as a potential delivery system for liposoluble nutrients. J Dairy Sci 92(6): 2524-2528.

Bjorkhem I, Meaney S. 2004. Brain cholesterol: long secret life behind a barrier. Arterioscler Thromb Vasc Biol 24(5): 806-815.

Boleman SL, et al. 1998. Pigs fed cholesterol neonatally have increased cerebrum cholesterol as young adults. J Nutr 128(12): 2498-2504.

Bonnet N, Ferrari SL. 2011. Effects of long-term supplementation with omega- 3 fatty acids on longitudinal changes in bone mass and microstructure in mice. J Nutr Biochem 22(7): 665-672.

Bonnet N, Ferrari S. 2015 A long-term diet enriched in omega-3 fatty acids improves cortical bone structure and mechanical properties in mice. Bone 44: S414.

Boucher O, et al. 2011. Neurophysiologic and neurobehavioral evidence of beneficial effects of prenatal omega-3 fatty acid intake on memory function at school age. Am J Clin Nutr 93(5): 1025-1037.

Bourlieu C, et al. 2015. The structure of infant formulas impacts their lipolysis, proteolysis and disintegration during in vitro gastric digestion. Food Chem 182: 224-235.

Breij LM, et al. 2017. Appetite-regulating hormones in early life and relationships with type of feeding and body composition in healthy term infants. Eur J Nutr 56(4): 1725-1732.

Brenna JT, Carlson SE. 2014. Docosahexaenoic acid and human brain development: evidence that a dietary supply is needed for optimal development. J Hum Evol 77: 99-106.

Brenna JT, et al. 2009. Alpha-linolenic acid supplementation and conversion to n-3 long-chain polyunsaturated fatty acids in humans. Prostagland Leukot Essent Fatty Acids 80(2-3): 85-91.

Brink LR, Gueniot JP, Lonnerdal B. 2019. Effects of milk fat globule membrane and its various components on neurologic development in a postnatal growth restriction rat model. J Nutr Biochem 69: 163-171.

Britton JR, Britton HL, Gronwaldt V. 2006. Breastfeeding, sensitivity, and attachment. Pediatrics 118(5): e1436-e1443.

Burdge GC, Wootton SA. 2002. Conversion of alpha-linolenic acid to eicosapentaenoic, docosapentaenoic and docosahexaenoic acids in young women. Br J Nutr 88(4): 411-420.

Campolongo P, et al. 2009. Fat-induced satiety factor oleoylethanolamide enhances memory consolidation. Proc Natl Acad Sci US A 106(19): 8027-8031.
Cao D, et al. 2009. Docosahexaenoic acid promotes hippocampal neuronal development and synaptic function. $J$ Neurochem 111 (2): $510-521$.

Carnielli VP, et al. 1998. Intestinal absorption of long-chain polyunsaturated fatty acids in preterm infants fed breast milk or formula. Am J Clin Nutr 67(1): 97-103.

Carrie I, et al. 2000. Specific phospholipid fatty acid composition of brain regions in mice. Effects of n-3 polyunsaturated fatty acid deficiency and phospholipid supplementation. J Lipid Res 41(3): 465-472.

Carrie I, et al. 2002. Docosahexaenoic acid-rich phospholipid supplementation: effect on behavior, learning ability, and retinal function in control and n-3 polyunsaturated fatty acid deficient old mice. Nutr Neurosci 5(1): 43-52.

Carver JD, et al. 2001. The relationship between age and the fatty acid composition of cerebral cortex and erythrocytes in human subjects. Brain Res Bull 56(2): 79-85.

Cato A, Hershey T. 2016. Cognition and type 1 diabetes in children and adolescents. Diabetes Spectr 29(4): 197-202.

Chalon S. 2006. Omega-3 fatty acids and monoamine neurotransmission. Prostagland Leukot Essent Fatty Acids 75(4-5): 259-269.

Chen CT, et al. 2015. Plasma non-esterified docosahexaenoic acid is the major pool supplying the brain. Sci Rep 5: 15791.

Clouard C, et al. 2015. Dietary linoleic and alpha-linolenic acids affect anxiety-related responses and exploratory activity in growing pigs. $J$ Nutr 145(2): 358-364.

Conklin SM, et al. 2010. Age-related changes of n-3 and n-6 polyunsaturated fatty acids in the anterior cingulate cortex of individuals with major depressive disorder. Prostagland Leukot Essent Fatty Acids 82(2-3): 111-119.

Contarini G, Povolo M. 2013. Phospholipids in milk fat: composition, biological and technological significance, and analytical strategies. Int J Mol Sci 14(2): 2808-2831.

Decsi T, Koletzko B. 1995. Growth, fatty acid composition of plasma lipid classes, and plasma retinol and alpha-tocopherol concentrations in full-term infants fed formula enriched with omega-6 and omega-3 long-chain polyunsaturated fatty acids. Acta Paediatr 84(7): 725-732.

Delgado-Noguera MF, Calvache JA, Bonfill Cosp X. 2010. Supplementation with long chain polyunsaturated fatty acids (LCPUFA) to breastfeeding mothers for improving child growth and development. Cochrane Database Syst Rev (12): Cd007901.

Delplanque B, et al. 2013. A dairy fat matrix providing alphalinolenic acid (ALA) is better than a vegetable fat mixture to increase brain DHA accretion in young rats. Prostagland Leukot Essent Fatty Acids 88(1): 115-120.

Demar JC Jr, et al. 2005. Alpha-linolenic acid does not contribute appreciably to docosahexaenoic acid within brain phospholipids of adult rats fed a diet enriched in docosahexaenoic acid. $J$ Neurochem 94(4): 1063-1076.

Deoni SC, et al. 2013. Breastfeeding and early white matter development: a cross-sectional study. Neuroimage 82: 77-86.

Deoni S, et al. 2018. Early nutrition influences developmental myelination and cognition in infants and young children. Neuroimage 178: 649-659.

DiSantis KI, et al. 2011. Do infants fed directly from the breast have improved appetite regulation and slower growth during early childhood compared with infants fed from a bottle? Int J Behav Nutr Phys Act 8: 89-89.

Duncan RE, Bazinet RP. 2010. Brain arachidonic acid uptake and turnover: implications for signaling and bipolar disorder. Curr Opin Clin Nutr Metab Care 13(2): 130-138. 
Dyall SC. 2015. Long-chain omega-3 fatty acids and the brain: a review of the independent and shared effects of EPA, DPA and DHA. Front Aging Neurosci 7: 52.

Efsa panel on dietetic products, N. and allergies. 2014. Scientific opinion on the essential composition of infant and follow-on formulae. EFSA $J$ 12(7): 3760-n/a.

Escolano-Margarit MV, et al. 2011. Prenatal DHA status and neurological outcome in children at age 5.5 years are positively associated. $J$ Nutr 141(6): 1216-1223.

Farquharson J, et al. 1992. Infant cerebral cortex phospholipid fattyacid composition and diet. Lancet 340(8823): 810-813.

Farr OM, Tsoukas MA, Mantzoros CS. 2015. Leptin and the brain: influences on brain development, cognitive functioning and psychiatric disorders. Metabolism 64(1): 114-130.

Field CJ. 2005. The immunological components of human milk and their effect on immune development in infants. J Nutr 135(1): 1-4.

Foot M, Cruz TF, Clandinin MT. 1982. Influence of dietary fat on the lipid composition of rat brain synaptosomal and microsomal membranes. Biochem J 208(3): 631-640.

Gallier S, et al. 2010. Using confocal laser scanning microscopy to probe the milk fat globule membrane and associated proteins. J Agric Food Chem 58(7): 4250-4257.

Gallier S, et al. 2015. A novel infant milk formula concept: mimicking the human milk fat globule structure. Colloids Surf B Biointerfaces 136: 329-339.

Garcia-Calatayud S, et al. 2005. Brain docosahexaenoic acid status and learning in young rats submitted to dietary long-chain polyunsaturated fatty acid deficiency and supplementation limited to lactation. Pediatr Res 57(5 Pt 1): 719-723.

German JB, Dillard CJ. 2010. Saturated fats: a perspective from lactation and milk composition. Lipids 45(10): 915-923.

Gibson RA, Muhlhausler B, Makrides M. 2011. Conversion of linoleic acid and alpha-linolenic acid to long-chain polyunsaturated fatty acids (LCPUFAs), with a focus on pregnancy, lactation and the first 2 years of life. Matern Child Nutr 7(Suppl. 2): 17-26.

Giovannini M, Riva E, Agostoni C. 1995. Fatty acids in pediatric nutrition. Pediatr Clin North Am 42(4): 861-877.

Giuffrida F, et al. 2013. Quantification of phospholipids classes in human milk. Lipids 48(10): 1051-1058.

Graf BA, et al. 2010. Age dependent incorporation of 14C-DHA into rat brain and body tissues after dosing various 14C-DHA-esters. Prostagland Leukot Essent Fatty Acids 83(2): 89-96.

Greiner RS, et al. 1999. Rats with low levels of brain docosahexaenoic acid show impaired performance in olfactory-based and spatial learning tasks. Lipids 34(Suppl.): S239-S243.

Grey KR, et al. 2013. Human milk cortisol is associated with infant temperament. Psychoneuroendocrinology 38(7): 1178-1185.

Grosso G, et al. 2014. Omega-3 fatty acids and depression: scientific evidence and biological mechanisms. Oxidative Med Cell Longevity 2014: 313570 .

Guan J, et al. 2015. Long-term supplementation with beta serum concentrate (BSC), a complex of milk lipids, during post-natal brain development improves memory in rats. Nutrients 7(6): 4526-4541.

Guaraldi F, Salvatori G. 2012. Effect of breast and formula feeding on gut microbiota shaping in newborns. Front Cell Infect Microbiol 2: 94.

Guillermo RB, et al. 2015. Supplementation with complex milk lipids during brain development promotes neuroplasticity without altering myelination or vascular density. Food Nutr Res 59: 25765.

Gulpinar MA, Yegen BC. 2004. The physiology of learning and memory: role of peptides and stress. Curr Protein Pept Sci 5(6): 457-473.
Gundberg CM, Lian JB, Booth SL. 2012. Vitamin K-dependent carboxylation of osteocalcin: friend or foe? Adv Nutr 3(2): 149-157.

Gurnida DA, et al. 2012. Association of complex lipids containing gangliosides with cognitive development of 6-month-old infants. Early Hum Dev 88(8): 595-601.

Gustavsson M, et al. 2010. Maternal supplementation with a complex milk lipid mixture during pregnancy and lactation alters neonatal brain lipid composition but lacks effect on cognitive function in rats. Nutr Res 30(4): 279-289.

Hadley KB, et al. 2016. The essentiality of arachidonic acid in infant development. Nutrients 8(4): 216.

Hamazaki K, Hamazaki T, Inadera H. 2013. Abnormalities in the fatty acid composition of the postmortem entorhinal cortex of patients with schizophrenia, bipolar disorder, and major depressive disorder. Psychiatr Res 210(1): 346-350.

Hamosh M, et al. 1985. Lipids in milk and the first steps in their digestion. Pediatrics 75(1 Pt 2): 146-150.

Harder T, et al. 2005. Duration of breastfeeding and risk of overweight: a meta-analysis. Am J Epidemiol 162(5): 397-403.

Hayatbakhsh MR, et al. 2012. Association of breastfeeding and adolescents' psychopathology: a large prospective study. Breastfeed Med 7(6): 480-486.

Heid HW, Keenan TW. 2005. Intracellular origin and secretion of milk fat globules. Eur J Cell Biol 84(2-3): 245-258.

Heikkila K, et al. 2014. Breastfeeding and educational achievement at age 5. Matern Child Nutr 10(1): 92-101.

Herba CM, et al. 2013. Breastfeeding and early brain development: the Generation R study. Matern Child Nutr 9(3): 332-349.

Hibbeln JR, et al. 2006. Healthy intakes of n-3 and n-6 fatty acids: estimations considering worldwide diversity. Am J Clin Nutr 83(6 Suppl.): 1483S-1493S.

Horta BL, Loret de Mola C, Victora CG. 2015. Breastfeeding and intelligence: a systematic review and meta-analysis. Acta Paediatr 104(467): 14-19.

Horwood LJ, Fergusson DM. 1998. Breastfeeding and later cognitive and academic outcomes. Pediatrics 101(1): E9.

Iacovou M, Sevilla A. 2013. Infant feeding: the effects of scheduled $v s$. on-demand feeding on mothers' wellbeing and children's cognitive development. Eur J Public Health 23(1): 13-19.

Igarashi M, et al. 2009. Dietary n-6 PUFA deprivation for 15 weeks reduces arachidonic acid concentrations while increasing n-3 PUFA concentrations in organs of post-weaning male rats. Biochim Biophys Acta 1791(2): 132-139.

Ikemoto A, et al. 2001. Reversibility of n-3 fatty acid deficiencyinduced alterations of learning behavior in the rat: level of n-6 fatty acids as another critical factor. J Lipid Res 42(10): 1655-1663.

Innis SM. 2003. Perinatal biochemistry and physiology of long-chain polyunsaturated fatty acids. J Pediatr 143(4 Suppl.): S1-S8.

Innis SM. 2007. Dietary (n-3) fatty acids and brain development. J Nutr 137(4): 855-859.

Jackson KM, Nazar AM. 2006. Breastfeeding, the immune response, and long-term health. J Am Osteopath Assoc 106(4): 203-207.

Jamieson EC, et al. 1999. Infant cerebellar gray and white matter fatty acids in relation to age and diet. Lipids 34(10): 1065-1071.

Jensen RG, et al. 1990. Lipids of bovine and human milks: a comparison. J Dairy Sci 73(2): 223-240.

Kafouri S, et al. 2013. Breastfeeding and brain structure in adolescence. Int J Epidemiol 42(1): 150-159.

Katakura M, et al. 2013. Omega-3 polyunsaturated fatty acids enhance neuronal differentiation in cultured rat neural stem cells. Stem Cells Int 2013: 490476. 
Kent JC, et al. 2006. Volume and frequency of breastfeedings and fat content of breast milk throughout the day. Pediatrics 117(3): e387-e395.

Kessler RC, et al. 2009. The global burden of mental disorders: an update from the WHO World Mental Health (WMH) surveys. Epidemiol Psichiatr Soc 18(1): 23-33.

Kitson AP, et al. 2016. Effect of dietary docosahexaenoic acid (DHA) in phospholipids or triglycerides on brain DHA uptake and accretion. J Nutr Biochem 33: 91-102.

Klerman GL, Weissman MM. 1989. Increasing rates of depression. JAMA 261(15): 2229-2235.

Kohlboeck G, et al. 2011. Effect of fatty acid status in cord blood serum on children's behavioral difficulties at 10 years of age: results from the LISAplus study. Am J Clin Nutr 94(6): 1592-1599.

Koletzko B, Rodriguez-Palmero M. 1999. Polyunsaturated fatty acids in human milk and their role in early infant development. J Mammary Gland Biol Neoplasia 4(3): 269-284.

Koletzko B, Thiel I, Abiodun PO. 1992. The fatty acid composition of human milk in Europe and Africa. J Pediatr 120(4 Pt 2): S62-S70.

Krabbendam L, et al. 2007. Relationship between DHA status at birth and child problem behaviour at 7 years of age. Prostagland Leukot Essent Fatty Acids 76(1): 29-34.

Kracun I, et al. 1992. Gangliosides in the human brain development and aging. Neurochem Int 20(3): 421-431.

Kris-Etherton PM, et al. 2000. Polyunsaturated fatty acids in the food chain in the United States. Am J Clin Nutr 71(1 Suppl.): 179S$188 \mathrm{~S}$

Kuipers RS, et al. 2005. High contents of both docosahexaenoic and arachidonic acids in milk of women consuming fish from lake Kitangiri (Tanzania): targets for infant formulae close to our ancient diet? Prostagland Leukot Essent Fatty Acids 72(4): 279-288.

Lassek WD, Gaulin SJ. 2014. Linoleic and docosahexaenoic acids in human milk have opposite relationships with cognitive test performance in a sample of 28 countries. Prostagland Leukot Essent Fatty Acids 91(5): 195-201.

Lauritzen L, et al. 2016. DHA effects in brain development and function. Nutrients $8(1)$

Lefkowitz W, et al. 2005. Where does the developing brain obtain its docosahexaenoic acid? Relative contributions of dietary alphalinolenic acid, docosahexaenoic acid, and body stores in the developing rat. Pediatr Res 57(1): 157-165.

Leventakou V, et al. 2015. Breastfeeding duration and cognitive, language and motor development at 18 months of age: Rhea mother-child cohort in Crete, Greece. J Epidemiol Community Health 69(3): 232-239.

Li R, Fein SB, Grummer-Strawn LM. 2008. Association of breastfeeding intensity and bottle-emptying behaviors at early infancy with infants' risk for excess weight at late infancy. Pediatrics 122(Suppl. 2): S77-S84.

Li R, Fein SB, Grummer-Strawn LM. 2010. Do infants fed from bottles lack self-regulation of milk intake compared with directly breastfed infants? Pediatrics 125(6): e1386-e1393.

Liu H, et al. 2014. Early supplementation of phospholipids and gangliosides affects brain and cognitive development in neonatal piglets. J Nutr 144(12): 1903-1909.

Liu JJ, et al. 2015. Pathways of polyunsaturated fatty acid utilization: implications for brain function in neuropsychiatric health and disease. Brain Res 1597: 220-246.

Liu L, et al. 2014. Higher efficacy of dietary DHA provided as a phospholipid than as a triglyceride for brain DHA accretion in neonatal piglets. J Lipid Res 55(3): 531-539.
Lopez C, Menard O. 2011. Human milk fat globules: polar lipid composition and in situ structural investigations revealing the heterogeneous distribution of proteins and the lateral segregation of sphingomyelin in the biological membrane. Colloids Surf $B$ Biointerfaces 83(1): 29-41.

Lopez C, et al. 2008. Phospholipid, sphingolipid, and fatty acid compositions of the milk fat globule membrane are modified by diet. J Agric Food Chem 56(13): 5226-5236.

Lucas A, et al. 1981. Metabolic and endocrine responses to a milk feed in six-day-old term infants: differences between breast and cow's milk formula feeding. Acta Paediatr Scand 70(2): 195-200.

MacIntosh BA, et al. 2013. Low-n-6 and low-n-6 plus high-n-3 diets for use in clinical research. Br J Nutr 110(3): 559-568.

Makrides M, et al. 1994. Fatty acid composition of brain, retina, and erythrocytes in breast- and formula-fed infants. Am J Clin Nutr 60 (2): 189-194.

Makrides M, et al. 1995. Changes in the polyunsaturated fatty acids of breast milk from mothers of full-term infants over $30 \mathrm{wk}$ of lactation. Am J Clin Nutr 61(6): 1231-1233.

Martinez M. 1992. Tissue levels of polyunsaturated fatty acids during early human development. J Pediatr 120(4 Pt 2): S129-S138.

Martinez M, Mougan I. 1998. Fatty acid composition of human brain phospholipids during normal development. J Neurochem 71(6): 2528-2533.

Martini M, Salari F, Altomonte I. 2016. The macrostructure of milk lipids: the fat globules. Crit Rev Food Sci Nutr 56(7): 1209-1221.

Mather IH, Keenan TW. 1998. Origin and secretion of milk lipids. J Mammary Gland Biol Neoplasia 3(3): 259-273.

Mathews SA, et al. 2002. Comparison of triglycerides and phospholipids as supplemental sources of dietary long-chain polyunsaturated fatty acids in piglets. J Nutr 132(10): 3081-3089.

Mauch DH, et al. 2001. CNS synaptogenesis promoted by gliaderived cholesterol. Science 294(5545): 1354-1357.

McJarrow P, et al. 2009. Influence of dietary gangliosides on neonatal brain development. Nutr Rev 67(8): 451-463.

McNamara RK. 2013. Deciphering the role of docosahexaenoic acid in brain maturation and pathology with magnetic resonance imaging. Prostagland Leukot Essent Fatty Acids 88(1): 33-42.

McNamara RK, et al. 2007. Selective deficits in the omega-3 fatty acid docosahexaenoic acid in the postmortem orbitofrontal cortex of patients with major depressive disorder. Biol Psychiatry 62(1): $17-24$.

Michaelsen KF, et al. 1992. Serum bone gamma-carboxyglutamic acid protein in a longitudinal study of infants: lower values in formula-fed infants. Pediatr Res 31(4 Pt 1): 401-405.

Michaelsen KF, Lauritzen L, Mortensen EL. 2009. Effects of breastfeeding on cognitive function. Adv Exp Med Biol 639: 199-215.

Michalski MC, et al. 2005. Size distribution of fat globules in human colostrum, breast milk, and infant formula. J Dairy Sci 88(6): 1927-1940.

Michalski MC, et al. 2006. The supramolecular structure of milk fat influences plasma triacylglycerols and fatty acid profile in the rat. Eur J Nutr 45(4): 215-224.

Michalski MC, et al. 2013. Multiscale structures of lipids in foods as parameters affecting fatty acid bioavailability and lipid metabolism. Prog Lipid Res 52(4): 354-373.

Mitchell RW, Hatch GM. 2011. Fatty acid transport into the brain: of fatty acid fables and lipid tails. Prostagland Leukot Essent Fatty Acids 85(5): 293-302.

Monnikes H, et al. 1997. Pathways of Fos expression in locus ceruleus, dorsal vagal complex, and PVN in response to intestinal lipid. Am J Physiol 273(6 Pt 2): R2059-R2071. 
Montgomery SM, Ehlin A, Sacker A. 2006. Breast feeding and resilience against psychosocial stress. Arch Dis Child 91(12): 990-994.

Morgan C, et al. 1998. Fatty acid balance studies in term infants fed formula milk containing long-chain polyunsaturated fatty acids. Acta Paediatr 87(2): 136-142.

Moriguchi T, Greiner RS, Salem N Jr. 2000. Behavioral deficits associated with dietary induction of decreased brain docosahexaenoic acid concentration. $J$ Neurochem 75(6): 2563-2573.

Morris MD, Chaikoff IL. 1961. Concerning incorporation of labelled cholesterol, fed to the mothers, into brain cholesterol of 20-dayold suckling rats. J Neurochem 8: 226-229.

Moukarzel S, et al. 2018. Milk fat globule membrane supplementation in formula-fed rat pups improves reflex development and may alter brain lipid composition. Sci Rep 8(1): 15277.

Muskiet FAJ. Frontiers in neuroscience. pathophysiology and evolutionary aspects of dietary fats and long-chain polyunsaturated fatty acids across the life cycle. In Montmayeur JP, Le Coutre J, eds. Fat detection: taste, texture, and post ingestive effects. Boca Raton (FL): CRC Press/Taylor \& Francis, Taylor \& Francis Group, LLC, 2010.

Muskiet FA, et al. 2004. Is docosahexaenoic acid (DHA) essential? Lessons from DHA status regulation, our ancient diet, epidemiology and randomized controlled trials. J Nutr 134(1): 183-186.

Muskiet FA, et al. 2006. Long-chain polyunsaturated fatty acids in maternal and infant nutrition. Prostaglandins Leukot Essent Fatty Acids 75(3): 135-144.

Neuringer M, et al. 1986. Biochemical and functional effects of prenatal and postnatal omega 3 fatty acid deficiency on retina and brain in rhesus monkeys. Proc Natl Acad Sci U S A 83(11): 4021-4025.

Novak EM, Dyer RA, Innis SM. 2008. High dietary omega-6 fatty acids contribute to reduced docosahexaenoic acid in the developing brain and inhibit secondary neurite growth. Brain Res 1237: 136-145.

O'Brien JS, Sampson EL. 1965. Lipid composition of the normal human brain: gray matter, white matter, and myelin. J Lipid Res 6 (4): 537-544.

Oddy WH, et al. 2010. The long-term effects of breastfeeding on child and adolescent mental health: a pregnancy cohort study followed for 14 years. J Pediatr 156(4): 568-574.

Ohlsson L, et al. 2014. Postprandial effects on plasma lipids and satiety hormones from intake of liposomes made from fractionated oat oil: two randomized crossover studies. Food Nutr Res 58.

Ortega-Anaya J, Jimenez-Flores R. 2019. Symposium review: the relevance of bovine milk phospholipids in human nutritionevidence of the effect on infant gut and brain development. J Dairy Sci 102(3): 2738-2748.

Oshida K, et al. 2003. Effects of dietary sphingomyelin on central nervous system myelination in developing rats. Pediatr Res 53(4): 589-593.

Oury F, et al. 2013. Maternal and offspring pools of osteocalcin influence brain development and functions. Cell 155(1): 228-241.

Palmano $\mathrm{K}$, et al. 2015. The role of gangliosides in neurodevelopment. Nutrients 7(5): 3891-3913.

Park EJ, et al. 2005. Diet-induced changes in membrane gangliosides in rat intestinal mucosa, plasma and brain. J Pediatr Gastroenterol Nutr 40(4): 487-495.

Plagemann A, et al. 2005. Impact of early neonatal breast-feeding on psychomotor and neuropsychological development in children of diabetic mothers. Diabetes Care 28(3): 573-578.
Polanczyk GV, et al. 2015. Annual research review: a meta-analysis of the worldwide prevalence of mental disorders in children and adolescents. J Child Psychol Psychiatry 56(3): 345-365.

Posse de Chaves E, Sipione S. 2010. Sphingolipids and gangliosides of the nervous system in membrane function and dysfunction. FEBS Lett 584(9):1748-1759.

Qawasmi A, et al. 2012. Meta-analysis of long-chain polyunsaturated fatty acid supplementation of formula and infant cognition. Pediatrics 129(6): 1141-1149.

Ramprasath VR, et al. 2013. Enhanced increase of omega-3 index in healthy individuals with response to 4 -week n-3 fatty acid supplementation from krill oil versus fish oil. Lipids Health Dis 12: 178.

Reis MM, et al. 2016. Effect of dietary complex lipids on the biosynthesis of piglet brain gangliosides. J Agric Food Chem 64 (6): 1245-1255.

Robson LG, et al. 2010. Omega-3 polyunsaturated fatty acids increase the neurite outgrowth of rat sensory neurones throughout development and in aged animals. Neurobiol Aging 31(4): 678-687.

Saarela T, Kokkonen J, Koivisto M. 2005. Macronutrient and energy contents of human milk fractions during the first six months of lactation. Acta Paediatr 94(9): 1176-1181.

Saher G, et al. 2005. High cholesterol level is essential for myelin membrane growth. Nat Neurosci 8(4): 468-475.

Salem N Jr., et al. 1996. Arachidonic and docosahexaenoic acids are biosynthesized from their 18-carbon precursors in human infants. Proc Natl Acad Sci U S A 93(1): 49-54.

Salmenpera L, et al. 1988. Effects of feeding regimen on blood glucose levels and plasma concentrations of pancreatic hormones and gut regulatory peptides at 9 months of age: comparison between infants fed with milk formula and infants exclusively breast-fed from birth. J Pediatr Gastroenterol Nutr 7(5): 651-656.

Sanders TA. 2000. Polyunsaturated fatty acids in the food chain in Europe. Am J Clin Nutr 71(1 Suppl.): 176S-178S.

Savino F, et al. 2009. Breast milk hormones and their protective effect on obesity. Int J Pediatr Endocrinol 2009: 327505.

Schipper L, et al. 2013. Postnatal dietary fatty acid composition permanently affects the structure of hypothalamic pathways controlling energy balance in mice. Am J Clin Nutr 98(6): 1395-1401.

Schipper L, et al. 2016. Reducing dietary intake of linoleic acid of mouse dams during lactation increases offspring brain n-3 LCPUFA content. Prostagland Leukot Essent Fatty Acids 110: 8-15.

Schipper L, et al. 2016. A postnatal diet containing phospholipids, processed to yield large, phospholipid-coated lipid droplets, affects specific cognitive behaviors in healthy male mice. $J$ Nutr 146(6): 1155-1161.

Simmer K, Schulzke SM, Patole S. 2008. Long-chain polyunsaturated fatty acid supplementation in preterm infants. Cochrane Database Syst Rev (1): Cd000375.

Simonin C, Ruegg M, Sidiropoulos D. 1984. Comparison of the fat content and fat globule size distribution of breast milk from mothers delivering term and preterm. Am J Clin Nutr 40(4): 820-826.

Singh H. 2006. The milk fat globule membrane - A biophysical system for food applications. Curr Opin Colloid Interface Sci 11 (2): $154-163$.

Skjodt H, et al. 1985. Vitamin D metabolites regulate osteocalcin synthesis and proliferation of human bone cells in vitro. J Endocrinol 105(3): 391-396. 
Slupsky CM, et al. 2017. Postprandial metabolic response of breastfed infants and infants fed lactose-free $v s$ regular infant formula: a randomized controlled trial. Sci Rep 7(1): 3640.

Tanaka K, et al. 2013. The pilot study: sphingomyelin-fortified milk has a positive association with the neurobehavioural development of very low birth weight infants during infancy, randomized control trial. Brain Dev 35(1): 45-52.

Timby N, et al. 2014. Neurodevelopment, nutrition, and growth until 12 mo of age in infants fed a low-energy, low-protein formula supplemented with bovine milk fat globule membranes: a randomized controlled trial. Am J Clin Nutr 99(4): 860-868.

Ulven SM, et al. 2011. Metabolic effects of krill oil are essentially similar to those of fish oil but at lower dose of EPA and DHA, in healthy volunteers. Lipids 46(1): 37-46.

van Aken GA. 2010. Relating food emulsion structure and composition to the way it is processed in the gastrointestinal tract and physiological responses: what are the opportunities? Food Biophys 5(4): 258-283.

van Driel M, van Leeuwen JPTM. 2014. Vitamin D endocrine system and osteoblasts. BoneKEy Rep 3: 493.

Vasquez-Garibay EM, et al. 2019. Serum concentration of appetiteregulating hormones of mother-infant dyad according to the type of feeding. Food Sci Nutr 7(2): 869-874.

Vickers MH, et al. 2009. Supplementation with a mixture of complex lipids derived from milk to growing rats results in improvements in parameters related to growth and cognition. Nutr Res 29(6): 426-435.

Victora CG, et al. 2015. Association between breastfeeding and intelligence, educational attainment, and income at 30 years of age: a prospective birth cohort study from Brazil. Lancet Global Health 3(4): e199-e205.

Wang B. 2012. Molecular mechanism underlying sialic acid as an essential nutrient for brain development and cognition. Adv Nutr 3 (3): $465 \mathrm{~S}-472 \mathrm{~S}$.

Wang B, et al. 2003. Brain ganglioside and glycoprotein sialic acid in breastfed compared with formula-fed infants. Am J Clin Nutr 78 (5): 1024-1029.

Wang B, et al. 2007. Dietary sialic acid supplementation improves learning and memory in piglets. Am J Clin Nutr 85(2): 561-569.

Watkins BA, et al. 2000. Dietary ratio of (n-6)/(n-3) polyunsaturated fatty acids alters the fatty acid composition of bone compartments and biomarkers of bone formation in rats. $J$ Nutr 130(9): 2274-2284.
World Health Organization (WHO) 2017. 10 facts on breastfeeding. At: http://www.who.int/features/factfiles/breastfeeding/en/.

Wijendran V, et al. 2002. Efficacy of dietary arachidonic acid provided as triglyceride or phospholipid as substrates for brain arachidonic acid accretion in baboon neonates. Pediatr Res 51(3): 265-272.

Williard DE, et al. 2001. Docosahexaenoic acid synthesis from n-3 polyunsaturated fatty acids in differentiated rat brain astrocytes. $J$ Lipid Res 42(9): 1368-1376.

Wolmarans P. 2009. Background paper on global trends in food production, intake and composition. Ann Nutr Metab 55(1-3): 244-272.

Wood KE, et al. 2013. Incorporating macadamia oil and butter to reduce dietary omega-6 polyunsaturated fatty acid intake. Nutr Diet 70(2): 94-100.

Wood KE, et al. 2014. A low omega- 6 polyunsaturated fatty acid (n-6 PUFA) diet increases omega-3 (n-3) long chain PUFA status in plasma phospholipids in humans. Prostagland Leukot Essent Fatty Acids 90(4): 133-138.

Wooding FB. 1971. The mechanism of secretion of the milk fat globule. J Cell Sci 9(3): 805-821.

Yam KY, et al. 2019. Increasing availability of omega-3 fatty acid in the early-life diet prevents the early-life stress-induced cognitive impairments without affecting metabolic alterations. FASEB J 33 (4): 5729-5740.

Ye A, Anema SG, Singh H. 2008. Changes in the surface protein of the fat globules during homogenization and heat treatment of concentrated milk. J Dairy Res 75(3): 347-353.

Youdim KA, Martin A, Joseph JA. 2000. Essential fatty acids and the brain: possible health implications. Int J Dev Neurosci 18(4-5): 383-399.

Yuhas R, Pramuk K, Lien EL. 2006. Human milk fatty acid composition from nine countries varies most in DHA. Lipids 41(9): $851-858$.

Zeisel SH. 2000. Choline: needed for normal development of memory. J Am Coll Nutr 19(5 Suppl.): 528S-531S.

Zeisel SH. 2004. Nutritional importance of choline for brain development. J Am Coll Nutr 23(6 Suppl.): 621S-626S.

Zhang J, Liu Q. 2015. Cholesterol metabolism and homeostasis in the brain. Protein Cell 6(4): 254-264.

Zou XQ, et al. 2012. Human milk fat globules from different stages of lactation: a lipid composition analysis and microstructure characterization. J Agric Food Chem 60(29): 7158-7167.

Cite this article as: Schipper L, Dijk Gv, Beek EMvd. 2020. Milk lipid composition and structure; The relevance for infant brain development. $O C L, 27: 5$. 